\title{
RESISTÊNCIA GENÉTICA DOS ACESSOS DO BANCO DE GERMOPLASMA DE MACIEIRA DA EPAGRI À MANCHA FOLIAR DE GLOMERELLA (Colletotrichum gloeosporioides) $^{1}$
}

\author{
CARLA REGINA COSTA FURLAN², ADRIANA CIBELE DE MESQUITA DANTAS ${ }^{3}$, \\ FREDERICO DENARDI ${ }^{4}$, WALTER FERREIRA BECKER ${ }^{5}$, ADELAR MANTOVANI ${ }^{6}$
}

RESUMO-Uma das prioridades do Programa de Melhoramento Genético de Macieira da Epagri é a obtenção de cultivares resistentes à mancha foliar de glomerella - MFG, doença essa causada principalmente pela espécie Colletotrichum gloeosporioides, que tem causado elevadas perdas na produção. Os resultados obtidos neste estudo têm, dentre outras, a finalidade de subsidiar os programas de melhoramento genético da macieira na seleção de parentais, objetivando a incorporação de resistência genética à MFG nas futuras novas cultivares. Para tanto, o primeiro passo é a identificação de germoplasma portador dos genes de resistência. No presente trabalho, foram utilizados 3 isolados de C. gloeosporioides provenientes de diferentes regiões produtoras de maçã. Estes isolados foram inoculados em 245 acessos pertencentes ao Banco de Germoplasma de Macieira - BGM, da Epagri / Estação Experimental de Caçador - EECd, SC. Para a inoculação em tecido foliar, a concentração de conídios foi ajustada para $10^{3}$ esporos $/ \mathrm{mL}$. Após $72 \mathrm{~h}$ de incubação, sob temperatura de $25^{\circ} \mathrm{C}$, foi realizada a avaliação da incidência para presença ou ausência de sintomas e para a severidade da doença. O delineamento experimental foi o inteiramente casualizado, com três repetições. As diferenças de severidade entre os acessos foram testadas através da Anova não paramétrica Kruskal Wallis. Entre os acessos testados, 187 (76,3\%) manifestaram resistência e $58(23,7 \%)$ suscetibilidade à MFG. Entre as cultivares suscetíveis, não houve diferença no grau de severidade de ataque da MFG.

Termos para indexação: Malus domestica Borkh, inoculação, acessos, resistência, suscetibilidade, melhoramento.

\section{GENETIC RESISTANCE OF ACCESSES OF APPLE TREE GERMPLASM BANK FROM EPAGRI TO GALA LEAF SPOT OF GLOMERELLA (Colletotrichum gloeosporioides)}

\begin{abstract}
One of the priorities at this moment of apple tree genetic breeding program in the south of Brazil is to obtain resistant cultures to Gala Leaf Spot (MFG) disease. This illness is caused mainly by the fungus Colletotrichum gloeosporioides, what has been causing great loss in the apple production. To solve this problem, the first step is to select the resistant germplasm that will supply the resistant genes. In this research it was used 3 isolates of $C$. gloeosporioides from different apple producer locations, and 245 samples belonging to the Apple Tree Active Germplasm Bank from the Experimental Station of EPAGRI in Caçador, Santa Catarina. For the inoculation of the leaf tissue, the concentration of the conidia was adjusted to $10^{3}$ spore $/ \mathrm{ml}$. After 72 hours of incubation at $25^{\circ} \mathrm{C}$, it was evaluated for the presence and absence of the symptom and its severity, through the diagrammatic scale. The experimental design was completely randomized with 3 repetitions. The severity differences among the samples were tested through the Anova non-parametric Kruskal Wallis test. Among the tested samples, 185 were resistant and 32 susceptible. From those susceptible, there was no difference in the severity degree of the MFG attack. The data obtained in this study can help in the choice of resistant samples that could be used as a parentage in the genetic breeding programs of apple tree, to obtain the resistance to this disease.
\end{abstract}

Index terms: Malus domestica Borkh, inoculation, sample, resistant, susceptible, breeding.

\footnotetext{
${ }^{1}$ (Trabalho 076-09). Recebido em: 03-04-2009. Aceito para publicação em: 20-11-2009. ${ }^{2}$ Bióloga M.Sc. Professora da FACVEST- Lages-SC. E-Mail: carlinhafurlan@gmail.com

${ }^{3}$ Eng. Agr. Dra. Professora da UERGS- UERGS/Bento Gonçalves-RS. E-Mail: adriana-dantas@uergs.edu.br

${ }^{4}$ Eng. Agr., M.Sc. EPAGRI/Estação Experimental de Caçador. E-Mail: denardi@epagri.sc.gov.br

${ }^{5}$ Eng. Agr., Dr. EPAGRI/Estação Experimental de Caçador. E-Mail: wbecker@epagri.sc.gov.br

${ }^{6}$ Eng. Agr. Dr. UDESC-Lages-SC. E-Mail. : mantovani@cav.udesc.br
} 


\section{INTRODUÇÃO}

A maçã é a fruta de clima temperado de maior dispersão, comercialização e consumo como fruta fresca no mundo, sendo a quarta frutífera mais produzida, perdendo somente para citros, uva e banana (HAUAGGE; BRUCKNER, 2002). A maçã Malus domestica pertence à família Rosaceae, que tem suas origens nas montanhas do Cáucaso, Oriente Médio e Leste Asiático. Bastante cultivada na Ásia e Europa desde os tempos mais antigos, é hoje cultivada em várias regiões do mundo, desde a Sibéria até as regiões altas dos trópicos (BLEICHER, 2006).

O Banco de Germoplasma de Macieira (BGM) da EPAGRI é composto de um amplo acervo de germoplasma, contendo 442 acessos que apresentam grande diversidade de características de importância agronômica, incluindo valiosa fonte de resistência às principais doenças da macieira, como a sarna (Venturia inaqualis), podridão-amarga (Glomerella spp. cingulata) e oídio (Podosphaera leucotricha), além da mancha foliar de glomerella (Colletotrichum spp). Para os programas de melhoramento genético, a coleta, a caracterização e a manutenção de germoplasma são indispensáveis para ampliar e preservar a variabilidade genética. Hammer (2003) afirma que um banco de germoplasma não pode ser um museu, devendo-se estimular a avaliação dos acessos por meio de análises genéticas. $\mathrm{O}$ manejo eficiente de germoplasma vegetal é de vital importância para o pesquisador, pois necessita que o mesmo se apresente geneticamente puro e bem caracterizado, para utilizá-lo em pesquisas e no melhoramento genético (MARTINELLO, et al.2001).

A mancha foliar de glomerella MFG é uma doença de grande importância no Brasil e também nos Estados Unidos, e as relações entre patógeno e hospedeiro ainda não são totalmente conhecidas. Desta forma, a diversidade genética presente nas coleções de germoplasma permite aos melhoristas escolher a melhor estratégia a ser empregada nos programas de melhoramento (LEFORT-BUSON et al., 1988).

O melhoramento genético da macieira é amplamente realizado na busca de melhor produtividade, sabor, aparência e armazenamento, mas é ainda deficiente na busca de resistência da espécie para muitas doenças e pragas (ALDWINCKLE, 2000). Apesar de a macieira ser uma das espécies de fruteiras mais consumidas, várias são as dificuldades encontradas no seu cultivo, dentre as quais a falta de adaptação das plantas em algumas regiões, devido a fatores edafoclimáticos relacionados à temperatura, altitude, precipitação, entre outros (PETRI, 2002).
O controle de doenças nos pomares de macieira no Sul do Brasil representa um dos principais itens nos custos de produção. A maciça aplicação de fungicidas, além de encarecer a produção de maçãs, tem efeitos danosos sobre o agroecossistema e sobre a saúde do consumidor. Dentre as alternativas de controle, a resistência genética, além de segura, tem baixo custo e ampla aceitação social, visto apresentar baixo impacto ambiental. Representa, por isto, um dos mais significativos avanços tecnológicos da agricultura. Segundo Borém (1997), o uso de cultivares resistentes é o método de controle preferido, simplesmente por ser o mais barato e de mais fácil utilização.

No Brasil, a cultura da macieira está sujeita ao ataque de inúmeras doenças, típicas de clima tropical, devido às condições climáticas marginais para o seu cultivo. Entre estas doenças, a mancha foliar da glomerella (MFG) é, atualmente, uma das duas doenças mais importantes da 'Gala' e de outras cultivares descendentes da 'Golden Delicious' (KATSURAYAMA, et al., 2001). A MFG manifesta-se a partir do final da primavera, reduzindo a produção quantitativa e qualitativamente (BONETTI et al., 1999). Os danos mais comuns são a desfolha da planta em 50 a 75\% e a formação de cancros em mais de $50 \%$ dos frutos (CEREZINE et al., 1992).

Em virtude da severidade de ataque e dos altos custos de controle, uma das prioridades atuais dos programas de melhoramento genético de macieira no Sul do Brasil é a obtenção de cultivares resistente à MFG. Neste processo, o passo inicial é a identificação de possíveis fontes de resistência existentes no Germoplasma disponível. Segundo pesquisas já realizadas (KATSURAYAMA et al., 2001), cultivares como a Fuji são portadoras de resistência de natureza monogênica e sob controle recessivo. Resultados de segregação observados em estudos envolvendo outras cultivares resistentes, como Imperatriz, Daiane e Baronesa, também apontam para este tipo de resistência (Denardi, comunicação pessoal). Inúmeras pesquisas em nível mundial, envolvendo fruteiras, têm revelado a ocorrência de quebra de resistências genéticas de natureza monogênica a fungos (OHM; SHANER, 1992).

Embora na literatura seja dito que a resistência genética do hospedeiro é, sem dúvida, o método mais eficiente, econômico e que menos riscos oferece à saúde do produtor, do consumidor e do ambiente (SARTORATO, 2006), é de fundamental importância que este recurso também ofereça proteção aos cultivos por longo tempo. Neste sentido, o objetivo deste trabalho foi investigar, primeiramente, a presença de novas fontes de resistência genética contra a MFG 
nos acessos do Banco de Germoplasma da Macieira da Epagri, em Caçador, e, numa segunda etapa, verificar a possível existência de fontes geneticamente diferenciadas de resistência nos diferentes acessos portadores desta característica.

\section{MATERIAL E MÉTODOS}

Para a inoculação dos isolados de Colletotrichum gloeosporioides, foram utilizados 245 acessos do Banco de Germoplasma da Macieira - BGM, da EPAGRI / Estação Experimental de Caçador. Na escolha do material, excluíram-se os acessos que se enquadravam nas seguintes situações: a) mutações somáticas das cultivares comerciais, cujo fator mutante não tem relação com a mancha foliar de glomerella - MFG; b) acessos de natureza silvestre, produtores de frutos muito pequenos - caráter dominante sobre tamanho comercial; c) acessos portadores de qualquer característica altamente indesejável para fins de melhoramento genético, como frutos de muito baixa qualidade, plantas de muito alto requerimento de frio hibernal e/ou muito suscetíveis a outros organismos fitopatogênicos, como a sarna ( $V$. inaequalis), oídio (P. leucotricha) e podridão-amarga ( $G$. cingulata).

Durante os meses de dezembro e janeiro de 2006/2007, foram coletados 4 ramos de crescimento do ano de cada acesso, com aproximadamente $40 \mathrm{~cm}$ de comprimento. Acondicionados em caixas de isopor contendo gelo, foram levados ao laboratório, preparados, deixando-se apenas as $6-8$ folhas mais novas do ápice caulinar. Imediatamente, foram colocados em potes contendo solução de água destilada, acrescida de $2,0 \%$ de açúcar, para evitar a desidratação dos ramos até o final do período de incubação.

Foram utilizados três isolados de Colletotrichum gloeosporioides provenientes de diferentes pomares de macieira, sendo um da região de Caçador (4355-6), um da região de Campo Tenente-PR (M-18) e um da região de Fraiburgo (M-15). Foram selecionados estes isolados com base em outros estudos de inoculação da MFG, nos quais apresentaram elevado índice de severidade de ataque (HAMADA, 2005). As colônias dos isolados foram mantidas em meio de cultura BDA (Batata-dextrose-ágar 39g/ L) durante 14 dias em BOD, sob regime de luz de $12 \mathrm{~h}$, por 14 dias, a $24^{\circ} \mathrm{C} \pm 1{ }^{\circ} \mathrm{C}$. A suspensão de esporos utilizada para as inoculações foi obtida através de raspagem superficial do micélio das placas de petri e filtragem em gaze esterilizada. As suspensões de esporos dos três isolados foram misturadas. Em seguida, foi realizada a contagem da concentração dos esporos com auxílio de hemacitômetro Neubauer e ajustada para $10^{3}$ conídios $/ \mathrm{mL}$, pela diluição em água destilada.
Foram realizadas duas inoculações: a primeira na totalidade das amostras dos 245 acessos do BGM, e a segunda somente nos acessos que apresentaram sintomas na primeira inoculação, por pulverização da suspensão de conídios utilizando um compressor de ar. Neste processo, o tempo de inoculação foi rigorosamente cronometrado, pulverizando-se as 5 ou 6 folhas mais novas do ápice caulinar, durante 10 segundos por acesso. Após a inoculação, os ramos foram borrifados com água destilada, repostos nos vasos e, em seguida, cobertos com sacos plásticos, para manter as folhas úmidas durante todo o período de incubação.

Após inoculados, os ramos foram mantidos sob incubação por 72 horas, em câmara úmida, com nebulização intermitente, no regime horário de 45 minutos desligada e 15 minutos ligada, mantendo o ambiente em $100 \%$ de UR. A temperatura foi mantida em $23^{\circ} \mathrm{C} \pm 1^{\circ} \mathrm{C}$. Na testemunha, foi empregada apenas água deionizada e esterilizada. Após $24 \mathrm{~h}$, os ramos foram novamente borrifados e assim mantidos por mais 24 horas. Após este período, os sacos plásticos foram removidos, e o regime de nebulização foi desligado. A avaliação da presença de sintomas de ataque da MFG nos ramos foi realizada 48h após, e depois de $24 \mathrm{~h}$ foi avaliada a severidade de ataque da doença com auxílio de uma escala diagramática (Becker, comunicação pessoal), onde $0=0 \% ; 1=3 \%$; $2=6 \% ; 3=12 \% ; 4=24 \% ; 5=>48 \%$ da superfície foliar com sintomas. Nesta avaliação, consideraramse apenas as cinco primeiras folhas a partir do ápice de cada ramo inoculado. Para a estimativa da severidade, utilizou-se a seguinte fórmula:

Severidade $(\%)=\frac{F 1 . n+F 2 . n+F 3 . n+F 4 . n+F 5 . n}{5.5}$

Em que: $\mathrm{F}$ = folha avaliada (1 a 5);

$n=$ nota atribuída.

Para o ensaio de inoculação, o delineamento experimental utilizado foi o inteiramente casualizado, sendo que cada ramo representou uma repetição, ou seja, foram feitas três repetições por acesso. Os dados foram submetidos à análise de variância para dados não paramétricos (Anova de Kruskal Wallis), a 5\% de significância. As diferenças de grau de severidade entre os acessos suscetíveis foram verificadas através do intervalo de confiança entre as amostras. 


\section{RESULTADOS E DISCUSSÃO}

No primeiro ensaio, em que foram inoculados 245 acessos do Banco de Germoplasma de Macieira - BGM, a mistura de isolados de Colletotrichum gloeosporioides foi patogênica para 58 acessos (Tabela 1), totalizando $23,7 \%$. Os demais 187 acessos (Tabela 2) mostraram-se resistentes à mancha foliar de glomerella - MFG, totalizando $76,3 \%$ do total inoculado. Os primeiros sintomas nos acessos suscetíveis foram observados 48 horas após a inoculação, quando as folhas apresentaram, inicialmente, pequenas lesões de coloração marromavermelhada, distribuídas de modo geral em toda a extensão da folha. Após 72 horas da inoculação, foi observado progresso das lesões e coalescência da área foliar afetada (Figura 1). Folhas da cv. Fuji não apresentaram sintomas, corroborando os resultados obtidos em inoculações realizadas por Hamada (2005), que observou sintomas somente na cv. Gala, inoculando diferentes isolados de Colletotrichum gloeosporioides, comprovando a suscetibilidade desta cultivar a esta doença, conforme Katsurayama e Bonetti (2002).

No segundo ensaio, foram inoculados apenas os acessos suscetíveis do BGM, com o objetivo de se avaliar a severidade de ataque da doença. Dos 58 acessos suscetíveis foram inoculados apenas 33 , que possibilitaram uma segunda coleta de material no campo. Entre as cultivares suscetíveis, houve diferenças significativas quanto ao percentual de severidade de ataque da MFG $\left(\mathrm{H}_{(33, \mathrm{~N}=99)}=55,99\right.$; $\mathrm{p}=0,0054)$. No entanto, conforme é mostrado na Figura 2, levando em conta o intervalo de confiança, as diferenças verificadas entre os acessos analisados não têm grande magnitude. Isto permite sugerir a relação de segregação resistente: suscetível é do tipo qualitativo, conforme descrita por Katsurayama et al. (2004). Katsurayama et al., (2001 e 2004) e Dantas et al., (2003) obtiveram resultados de populações de cruzamentos envolvendo combinações de cultivares resistentes e suscetíveis, que apontam para um controle monogênico recessivo. A confirmação da segregação monogênica recessiva, para resistência à MFG em macieira, certamente limitaria o uso deste mecanismo de controle em nível comercial, devido ao iminente risco de quebra da resistência por formas mutantes (novas raças) deste patógeno, como ocorre com a sarna e o oídio da macieira (SILVA, 2007). Por outro lado, não há relatos de que tenham sido conduzidas anteriormente pesquisas para resistência à MFG.

Entretanto, em trabalhos posteriores realizados por Dantas et al. (2005), com inoculações de $C$. gloeosporoides em diferentes populações segregantes de cruzamentos envolvendo cultivares resistentes e suscetíveis, incluindo Gala e Fuji, os autores inferiram a presença de três genes que segregam de forma independente, sendo um dominante e dois recessivos, que atuam de forma complementar.

Ainda que desvios das proporções esperadas para segregação monogênica tenham sido observados em alguns cruzamentos, sugerindo que outros fatores estejam influenciando na resposta da macieira ao Colletotrichum, segundo Silva (2007), pouco se sabe a esse respeito. Apesar da enorme variabilidade genética existente no gênero Malus, o melhoramento tem sido realizado somente com um limitado pool gênico; com o agravante do foco, apenas há características de importância comercial, negligenciando os aspectos fitossanitários. Desta maneira, grande número de cultivares comerciais derivaram de cruzamentos nos quais um dos genitores foi a 'Golden Delicious', suscetível à MFG, e/ou a 'Cox's Orange Pippin' (NOITON; SHELBOURNE, 1992), cujos frutos são muito apreciados pelos consumidores.

Alguns dos genótipos do BGM que se mostraram suscetíveis à MFG, Condessa, Duquesa, Elstar, Gala, Galícia, Hatsuaki, Horei, Jonafree, Jonagold, Kogetsu, Lisgala, Mutsu, Odin, Pink Lady, Rainha, Summerred, Spigold e Yvette possuem parentesco direto com a Golden Delicious, confirmando este dado.

Nos resultados deste estudo, a maioria dos genótipos existentes no BGM de Caçador é resistente à MFG (Tabela 2), incluindo muitos genótipos descendentes de, pelo menos, um parental suscetível, como a Golden Delicious. Resultados obtidos com inoculações artificiais realizadas na Epagri (DENARDI, 2007 - informação pessoal), indicaram que as cultivares Anna e Sansa, descendentes em F1 da Golden Delicious, e as cultivares Imperatriz e Daiane, descendentes em F2, são todas resistentes.

Estudos realizados sobre a genealogia dos genótipos existentes no BGM de Caçador mostram que vários acessos com parentesco direto com a Golden Delicious apresentaram resistência à MFG. Cita-se Arlet, Carícia, Ein Shemer, Greensleeves, Hawaii, Honey Gold, Red Gold, Sweet Cornelly, Shel Red, Summerland, Tsugaru e Yoko. Por outro lado, poucos acessos descendentes da Delicious, que é resistente à $\mathrm{MFG}$, apresentaram suscetibilidade no presente estudo, como os genótipos Senshu e Aori.

Apesar de o screening ter sido realizado apenas em acessos com características próximas às variedades cultivadas, os demais acessos do Banco serão estudados posteriormente a fim de verificar seu comportamento em relação à MFG e estudos comple- 
mentares estão sendo conduzidos com o auxílio de técnicas de biologia celular e molecular, objetivando investigar a possível existência de diferentes fontes de resistência à MFG.

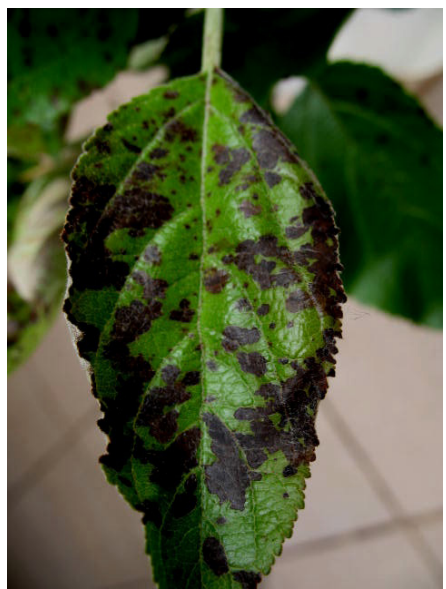

Cv. Akagui 72h após a incubação

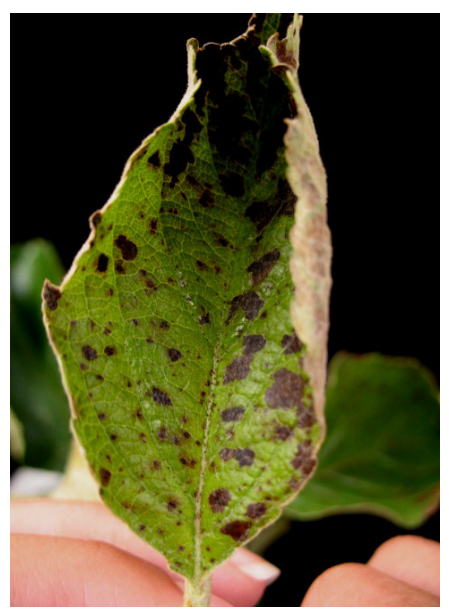

Cv. Kogetsu

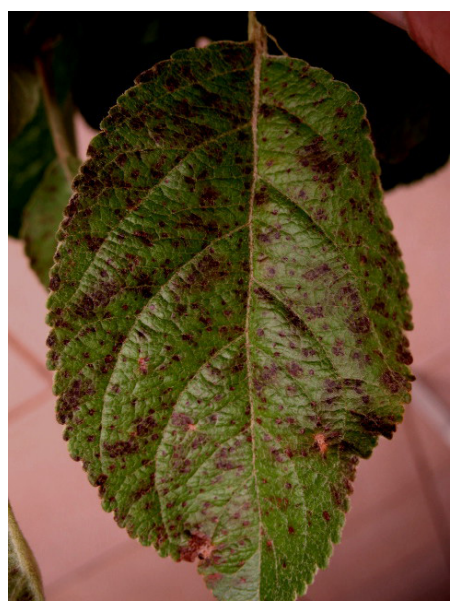

Cv. Odin

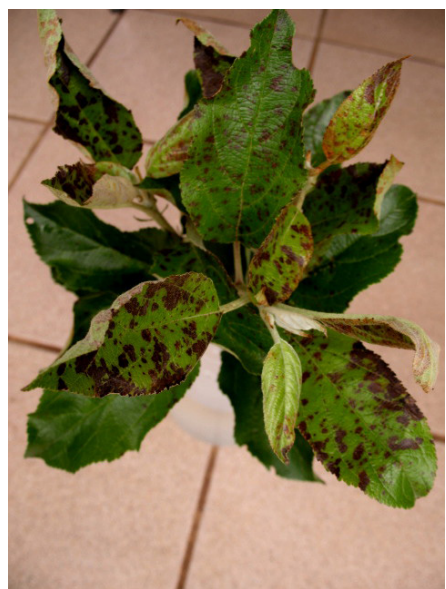

Ramo da cv. Akagui 72h após

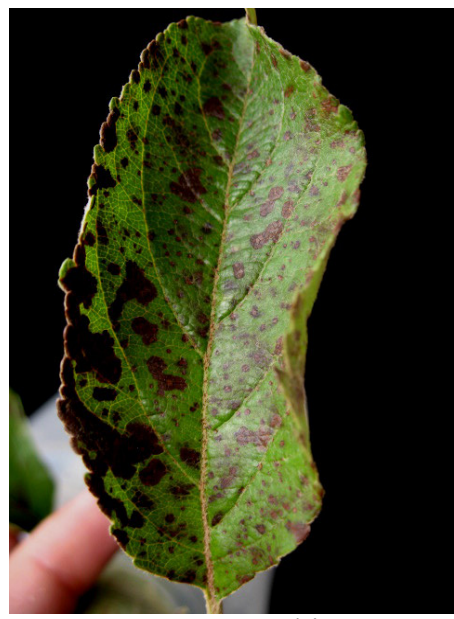

Cv. Hatsuaki

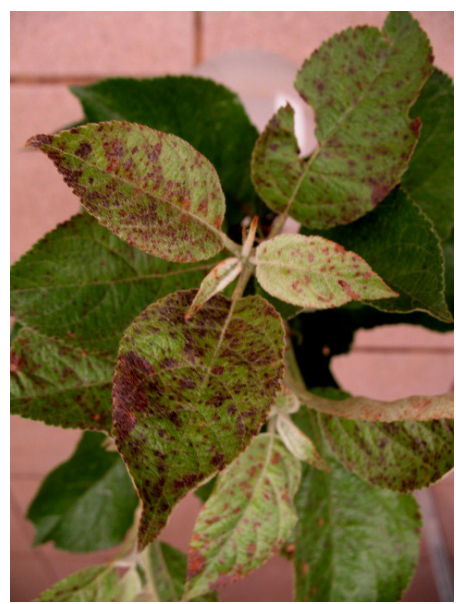

Ramo Cv. Odin

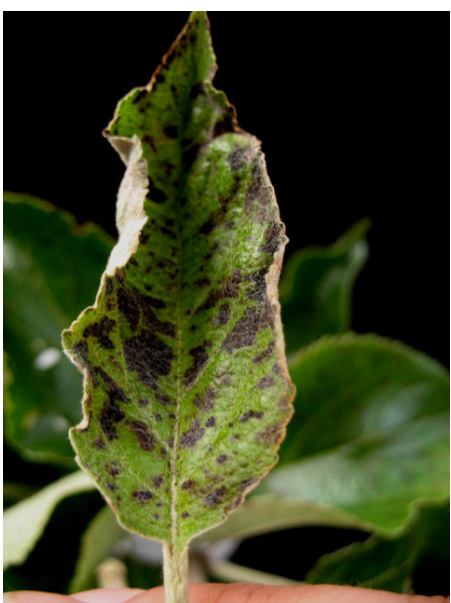

Cv. Mizuso Tsugaru

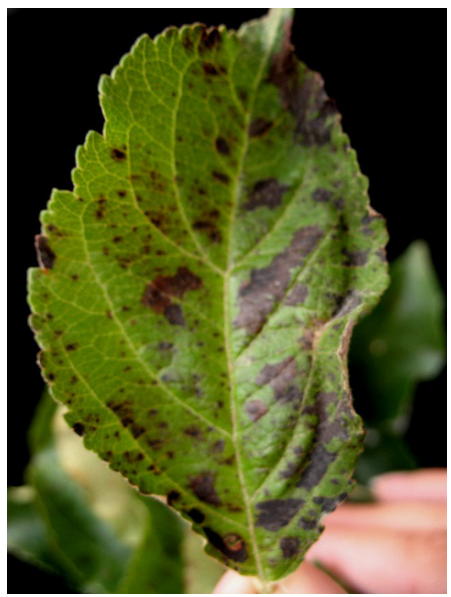

Cv. Pink Lady

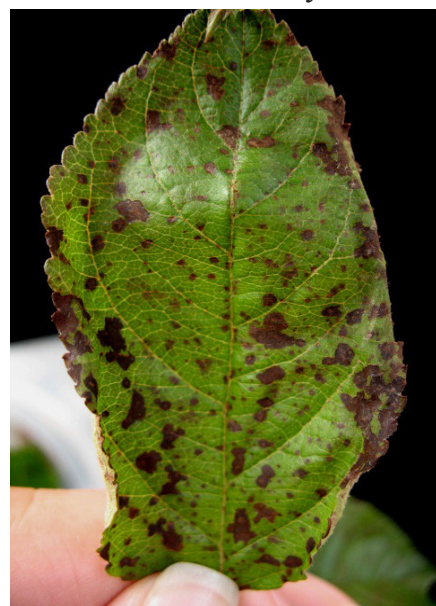

Cv. Splendor

FIGURA 01- Folhas e ramos de macieira com sintomas diferenciados da mancha foliar de Glomerella após 72 horas da inoculação. 


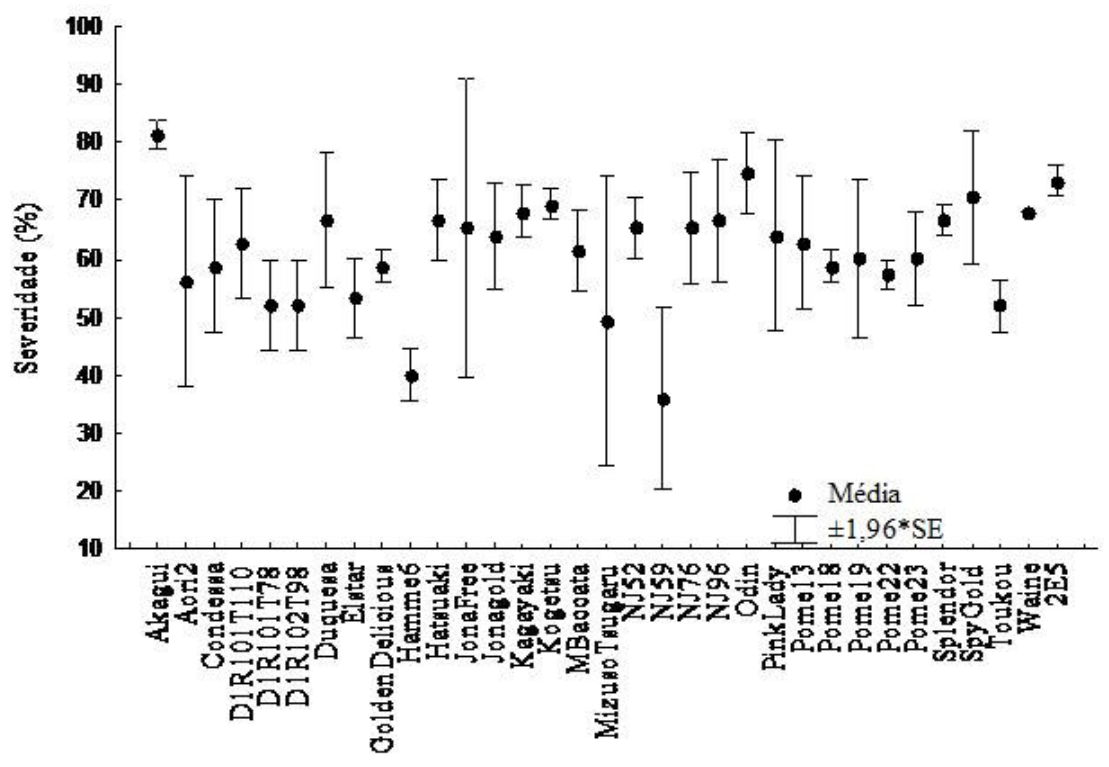

Acessos

FIGURA 02- Diferença de severidade (\%) dos genótipos suscetíveis à Mancha Foliar de Glomerella do Banco de Germoplasma de Maçã (BGM) da Epagri / Estação Experimental de Caçador - EECd, SC, 2008.

TABELA 1 - Relação de genótipos existentes no Banco de Germoplasma de Macieira da Epagri / Estação Experimental de Caçador, portadores de suscetibilidade à mancha foliar de Glomerella.

GENÓTIPOS SUSCETÍVEIS DO BGM EPAGRI/CAÇADOR

\begin{tabular}{lclclclc}
\hline 1 & Akagui & 16 & Hatsuaki & 31 & NJ 59 & 46 & Pome 23 \\
2 & Condessa & 17 & Horey & 32 & Nero 26 & 47 & PX 216 \\
3 & D1R99T188 & 18 & Ivette & 33 & NJ-45 & 48 & PX 565 \\
4 & D1R100T209 & 19 & Jona Free & 34 & NJ-52 & 49 & PX 1032 \\
5 & D1R101T110 & 20 & Jonagold & 35 & NJ-76 & 50 & Rainha \\
6 & D1R101T78 & 21 & Kagayaki & 36 & NJ-96 & 51 & Senshu \\
7 & D1R102T98 & 22 & Kogetsu & 37 & Odama Oley & 52 & Splendor \\
8 & D1R98T486 & 23 & Lisgala & 38 & Odin & 53 & Spy Gold \\
9 & Discovery & 24 & M. Baccata & 39 & Ozark Gold & 54 & Summered \\
10 & Duquesa & 25 & Marquesa & 40 & Pink Lady & 55 & Toukou \\
11 & Elstar & 26 & Misouri 2071 & 41 & Planaltina & 56 & Willie Sharp \\
12 & G. Weinsberg & 27 & Mizuso Tsugaru & 42 & Pome 13 & 57 & Wilmuta \\
13 & Gala & 28 & Mutsu & 43 & Pome 18 & 58 & \\
14 & Granny Smith & 29 & Mizuso Tsugaru & 44 & Pome 19 & & \\
15 & Hamme 6 & 30 & Mutsu & 45 & Pome 22 & & \\
\hline
\end{tabular}


TABELA 2 - Relação de genótipos existentes no Banco de Germoplasma de Macieira da Epagri / Estação Experimental de Caçador, portadores de resistência à mancha foliar de Glomerella.

\section{GENÓTIPOS RESISTENTES DO BGM EPAGRI/CAÇADOR}

\begin{tabular}{|c|c|c|c|c|c|c|c|}
\hline 1 & 21.300 .21 & 48 & Dorsett Golden & 97 & M-6039 & 146 & PX 647 \\
\hline 2 & 21.300 .13 & 49 & Dulcina & 98 & Maayan & 147 & PX 663 \\
\hline 3 & 21.361 .75 & 50 & Early Styman & 99 & Mac Free & 148 & PX 1033 \\
\hline 4 & 21.373 .58 & 51 & Ein Shemer & 100 & Malus eley & 149 & Quinte \\
\hline 5 & 21.379 .64 & 52 & Empire & 101 & Mechinoku & 150 & Red Free \\
\hline 6 & 21.502 .1 & 53 & Ervin & 102 & Melrose & 151 & Red Delicious \\
\hline 7 & 21.555 .13 & 54 & Eva & 103 & Mere & 152 & Well Spur \\
\hline 8 & Akane & 55 & Everest & 104 & Milton & 153 & Red Gold \\
\hline 9 & Alkmene & 56 & Fiesta & 105 & Monroe & 154 & Red June \\
\hline 10 & Angius & 57 & Florina & 106 & N.Easygro & 155 & Red Rome \\
\hline 11 & Annurca & 58 & FR 8 & 107 & Natsumidori & 156 & Reinete Canada \\
\hline 12 & Argentina 2 & 59 & FR 16 & 108 & Nebuta & 157 & Reinete du Mans \\
\hline 13 & Arlet & 60 & Fred Hough & 109 & Nero Red Rome & 158 & Rene Reinetes \\
\hline 14 & B. Boscoop & 61 & Fuji Suprema & 110 & Newton Pippin & 159 & Romy 50 \\
\hline 15 & Baldwin & 62 & Galícia & 111 & Niagara & 160 & Ruby Spur \\
\hline 16 & Baronesa & 63 & Gloster 69 & 112 & Nippling Staymann & 161 & Sansa \\
\hline 17 & Belfigrigiole & 64 & Gold John & 113 & Nitany & 162 & Shell Red \\
\hline 18 & Bem Davis & 65 & Goltey & 114 & NJ-36 & 163 & SM 69-2 \\
\hline 19 & Black Stayman & 66 & Gorden & 115 & NJ-41 & 164 & SM 69-3 \\
\hline 20 & Blackjon & 67 & Grangile Red & 116 & NJ-44 & 165 & SM 78-2 \\
\hline 21 & Bonita & 68 & Greensleeves & 117 & NJ-45 & 166 & SM 82-1 \\
\hline 22 & Braeburn & 69 & Grive Rouge & 118 & NJ-49 & 167 & Spartan \\
\hline 23 & Brasil & 70 & Groth Red & 119 & NJ-50 & 168 & Stark J. Gremes \\
\hline 24 & Carícia & 71 & Harold Red & 120 & NJ-51 & 169 & Stark Jonadel \\
\hline 25 & Carla & 72 & Hawai & 121 & NJ-55 & 170 & Staymann \\
\hline 26 & Catarina & 73 & Hamme 6 & 122 & NJ-75 & 171 & Summerland \\
\hline 27 & Centenária & 74 & Hokuto & 123 & Nova Mac & 172 & Sungold \\
\hline 28 & Close & 75 & Holliday & 124 & Ohrin & 173 & Suntan \\
\hline 29 & Conrad Red & 76 & Holland & 125 & Orankis Ten & 174 & Super Kidd's \\
\hline 30 & Coop 8 & 77 & Holly & 126 & Pachacamac & 175 & Sweet Cornelly \\
\hline 31 & Coop 14 & 78 & Honey Gold & 127 & Pacific Rose & 176 & Trop. Beauty \\
\hline 32 & Coop 16 & 79 & Imperatore & 128 & Paulared & 177 & Tsugaru \\
\hline 33 & Coop 24 & 80 & Imperatriz & 129 & Pilat & 178 & Ultrared \\
\hline 34 & D1R103T245 & 81 & Israel 8-3 & 130 & Pome 3 & 179 & Vered \\
\hline 35 & D1R102T116 & 82 & Jamba & 131 & Pome 10 & 180 & Waine \\
\hline 36 & D1R63T94 & 83 & Jersey Mac & 132 & Pome 12 & 181 & W. Banana \\
\hline 37 & D1R68T571 & 84 & Jona Mac & 133 & Pome 14 & 182 & Wealthy \\
\hline 38 & D1R78T2 & 85 & Jonared & 134 & Pome 15 & 183 & Webster \\
\hline 39 & D2R30T30 & 86 & Jonathan & 135 & Pome 16 & 184 & Wemmerschok \\
\hline 40 & D2R31T237 & 87 & José Bins & 136 & Pome 17 & 185 & Winter Gold \\
\hline 41 & D2R38T126 & 88 & July Red & 137 & Pome 20 & 186 & Yoko \\
\hline 42 & D2R39T243 & 89 & Kendall & 138 & Pome 24 & 187 & Ziger \\
\hline 43 & D2R40T253 & 90 & Kent & 139 & Pome 25 & & \\
\hline 44 & D2R40T258 & 91 & Kitanosaki & 140 & Pome 28 & & \\
\hline 45 & Daiane & 92 & Liberty & 141 & Porporate & & \\
\hline 46 & Delcon & 93 & M. aldenhamensis & 142 & Priam & & \\
\hline \multirow[t]{3}{*}{47} & Delícia & 94 & M. atrosanguinea & 143 & Princesa & & \\
\hline & & 95 & M. floribunda & 144 & Priscilla & & \\
\hline & & 96 & M. robusta & 145 & PX 322 & & \\
\hline
\end{tabular}




\section{CONCLUSÕES}

1-Os acessos do BGM não apresentam diferenças significativas quanto à resistência ao $C$. gloreosporiodes.

2-Com base nestes resultados, as cv. de maçã que levam genes de resistência para este patógeno, serão de grande valia para serem usadas como material original no desenvolvimento de variedades novas.

\section{REFERÊNCIAS}

ALDWINCKLE, H.; Norelli, J. Improvement of AppleVarieties and Rootstocks by Biotechnology. Presented at the 43rd Annual IDFTA Conference, Napier, New Zealand February 6-9, 2000.

BLEICHER, J. História da Macieira. p. 29-36. In. EPAGRI. A cultura da macieira. Florianópolis-SC, 743p., 2006.

BONETTI, J.I.S.; OZAWA, T. Efeito da temperatura e do período de molhamento foliar na severidade da mancha foliar de Glomerella nas macieiras da cv. Gala, em condições controladas. Fitopatologia Brasileira, v. 24, n. suplemento, p. 295-296, 1999.

BORÉM, A. Melhoramento visando à resistência a doenças. In: BORÉM, A. Melhoramento de plantas. Viçosa: Editora UFV, 1997. 461-484.

CEREZINE, P.C.; LEITE, R.P.; TSUNETA, M. Efeito do tratamento químico no controle da mancha foliar de Glomerella em macieira no Estado do Paraná. Fitopatologia Brasileira 17(3): 258-267, 1992.

DANTAS, A.C.M.; BONETI, J. I.; KATSURAYAMA, Y.; NODARI, R.O. Herança da resistência da Mancha Foliar (Colletotrichum Gloeosporioides Penz.) em macieira. In: CONGRESSO BRASILEIRO MELHORAMENTO DE PLANTAS, 2., Porto Seguro-BA, 2003. Anais... Porto Seguro-BA, 2003.

DANTAS, A.C.M.; VIEIRA, E.A.; NODARI, R.O.; KATSURAYAMA, Y.; BONETI, J. I. Classificação e estudo da herança de resistência Colletotrichum Gloeosporioides, agente causador da Mancha Foliar em macieira. In: CONGRESSO BRASILEIRO DE GENÉTICA, 51., Águas de Lindoia, 2005. Anais... Águas de Lindoia, 2005.

HAMADA, N.A. Influência da temperatura e do período de molhamento foliar (PMF) na incidência e severidade da Mancha Foliar da Gala (Colletotrichum spp.). Agropecuária Catarinense 18(2), p.73-77. 2005.
HAMMER, K.A. Paradigm shift in the discipline of plant genetic resources. Genetic Resources and Crop Evolution, v.50, p.3-10, 2003.

HAUAGGE, R.; BRUCKNER, C. H. Macieira. cap. 2, p.28-88. In. BRUCKNER, C. H.Melhoramento de Fruteiras de Clima Temperado. Editora Viçosa:UFV, 2002.

KATSURAYAMA, Y.; BONETI, J.I. da S. Efeito da temperatura na germinação de conídios de Colletotrichumspp in Relatório Técnico ABPM - Projetos de Pesquisas 2001-2002. Fraiburgo: ABPM, 2002.

KATSURAYAMA, Y.; BONETI, J.I.S.; BECKER, W. F. Prevenção e controle da Mancha da Gala. In: SEMINÁRIO SOBRE FRUTICULTURA DE CLIMA TEMPERADO, 5., 2004. São Joaquim-SC. Anais...Epagri, Florianópolis-SC. 2004,74p.

KATSURAYAMA, Y.; TSUCHIYA, S.; BONETI, J.I.S. Herança da resistência da macieiras à mancha da Gala (Colletotrichum goeosporioides). Fitopatologia Brasileira, v.26, p.409, 2001.

LEFORT-BUSON, M.; HEBERT, Y.; DAMERVAL, $\mathrm{K}$. Les outils d'évaluation de la diversité génétique at phenotypique. Agronomie, 8,p.173-178, 1988.

MARTINELLO, G.E.; LEAL, N.R.; AMARAL JÚNIOR, A.T.; PEREIRA, M.G.; DAHER, R.F. Divergência genética em acessos de quiabeiro com base em marcadores morfológicos. Horticultura Brasileira, Brasília, v. 20, n. 1, p. 52-58, março 2001.

NOITON, D.; SHELBOURNE, C.J.A. Quantitative genetics in an apple breeding strategy. Euphytica, v.60, p.213-219, 1992.

OHM, H. W.; SHANER, G. Breeding oat for resistance to diseases. In: MARSHALL, H. G.; SORRELLS, M. E. (Ed.). Oat science and technology. Madison: American Society of Agronomy/Crop Science Society of America (Agronomy Monograph, 33), 1992. p. 657-698.

PETRI, J.L. Fatores edafoclimáticos. In: A Cultura da Macieira. Florianópolis, 2002. 743p.

SARTORATO, A. Novas Fontes de Resistência do Feijoeiro Comum à Mancha Angular. Fitopatologia Brasileira. 31(2), mar. - abr. 2006.

SILVA, M. F. da. Desenvolvimento de um mapa genético de ligação de macieira saturado para a região com resistência à Mancha Foliar de Glomerella (Colletotrichum gloeosporioides).Tese. Universidade Federal de Santa Catarina, novembro de 2007. 